\title{
EDITORIAL
}

\section{Me, the transplant and the ICU: a patient's story}

\author{
Geoffrey Bonosevich* (10)
}

(c) 2018 Springer-Verlag GmbH Germany, part of Springer Nature and ESICM

As an active 45 year old in the middle of my career, a non-smoker with ideal weight and Body Mass Index (BMI) and a participant in half-marathons, the last place I expected to end up was in a hospital, let alone in an Intensive Care Unit (ICU). My previous hospital exposure was highly limited. But that would change suddenly in 2003, after I started noticing that something wasn't quite right with my health.

The night before a business trip, shortly before going to bed, I suddenly felt extremely dizzy and then quickly lost consciousness and collapsed. Thanks to the immediate actions of my family and two doctors from our neighborhood, I quickly regained consciousness and was immediately brought to the hospital by ambulance.

The diagnosis was atrioventricular block level III. A pace maker was implanted and I soon lost sight in my right eye due to an embolic optic nerve stroke. This was the beginning of an ordeal spanning 10 years and a tremendous shock to both me and my family. We had no idea of the consequences on our lives and couldn't imagine that my condition would deteriorate to the point that I would require a heart transplant.

Within the next months and years, additional problems would arise which would all have a major impact on my quality of life. These included ventricular tachycardia and the need for an implantable cardioverter defibrillator, the horrible shocks that followed, numerous changes to my medication and several hospital visits. I was then diagnosed with dilated cardiomyopathy.

It was clear that my condition had worsened considerably. I felt constantly exhausted and lost my breath easily after the slightest exertion. My normal weight dropped to $62 \mathrm{~kg}$ and my left ventricular ejection fraction had sunk

*Correspondence: geoffrey.bonosevich@gmx.de

Hofweg 18, 93053 Regensburg, Germany to below $15 \%$ (the normal value is above $55 \%$ ). At this point, my New York Heart Association functional classification was level III. In 2010, my doctors began evaluating my condition to see if I would qualify to be listed for a heart transplant. It was soon decided that I was eligible for a High Urgency (HU) listing.

During a hospital stay in January 2011, I suffered an acute decompensation. Gasping heavily for air and

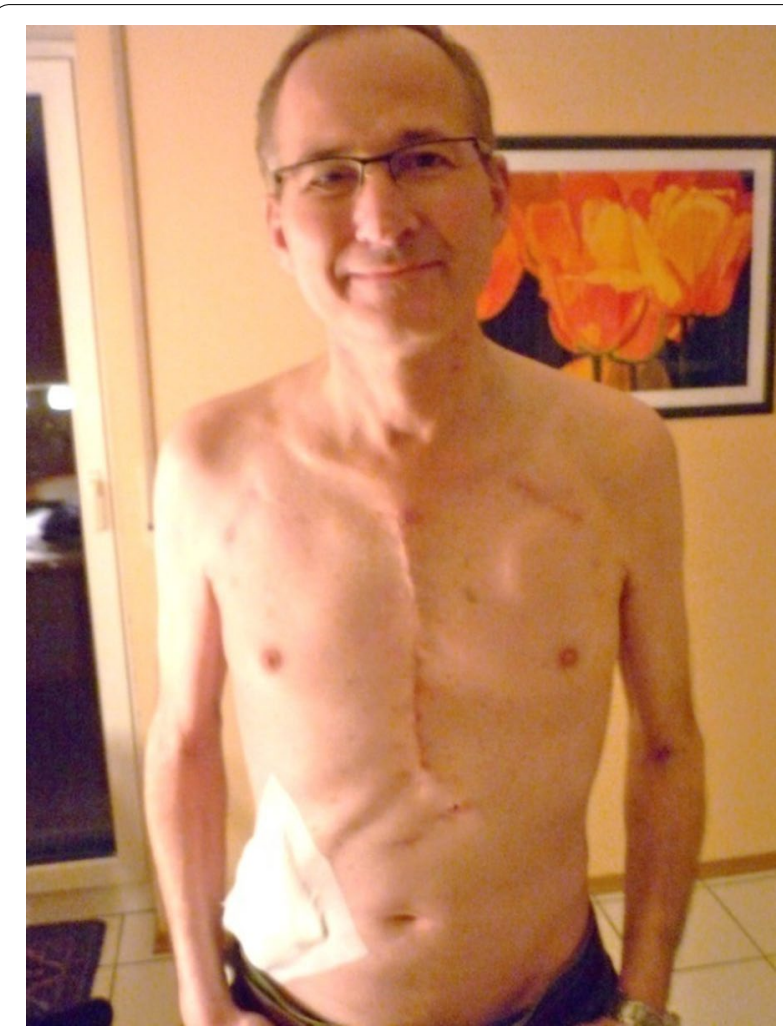

Fig. 1 February 2011 after my left ventricular assist device operation 


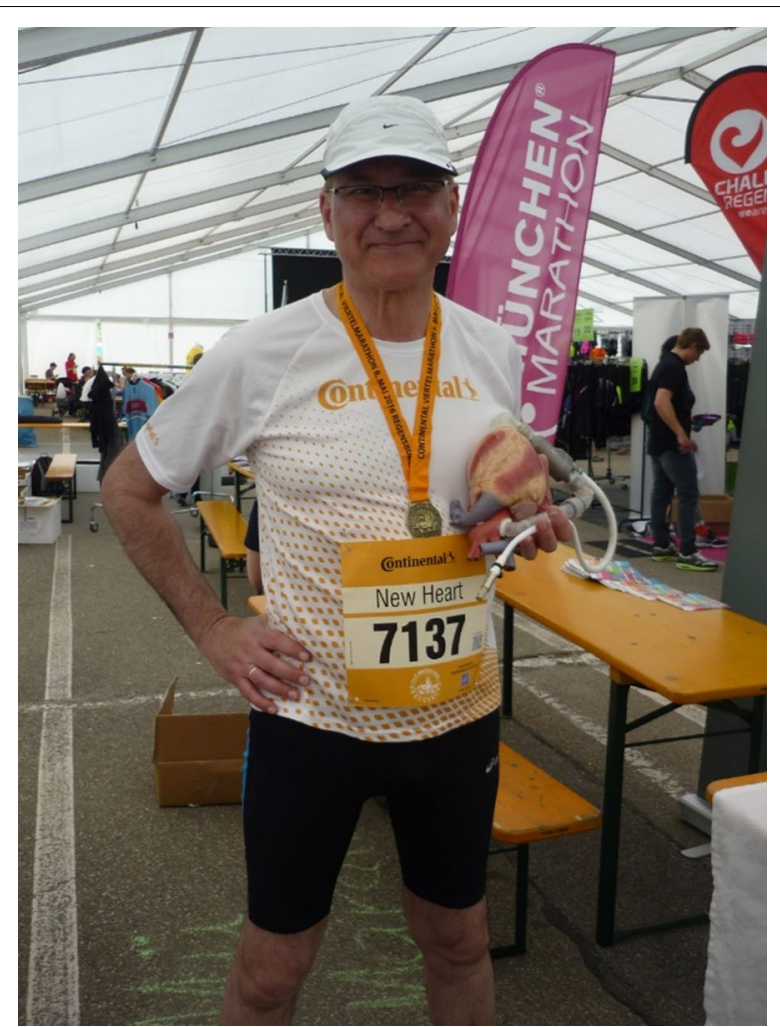

Fig. 2 May 2018 after my third quarter marathon in Regensburg, Germany, since 2012. The heart model and INCOR ${ }^{\circledR}$ left ventricular assist device are courtesy of Berlin Heart $\mathrm{GmbH}$

completely weakened, the last thing I remember hearing from my surgeon, Professor Stephan Hirt, was "we're going to have to move you to the ICU". He then reanimated me.

After 3 days of slowly waking up, I found myself surrounded by machines and wired to monitoring units. Attached to the bed was a large electromechanical device, which, I would be told, was an Extracorporeal Membrane Oxygenation (ECMO) unit. Two thick transparent tubes filled with blood connected me to the ECMO. The device was only a bridge therapy until I could receive my left ventricular assist device (LVAD), which took place 12 days later (Fig. 1 ).

I was now fully and completely dependent on the expertise of the women and men in the ICU and their monitoring and life support devices. It was indeed a very strange situation to be in. There was always something beeping and various lights flashing on the monitors, which made sleeping very difficult, but, then again, I had so many existential things on my mind that I wouldn't have been able to sleep in my own, quiet bedroom at home either.

Being an engineer (aerospace technology), I wanted to know everything about the LVAD I was soon to receive. I requested not just for some flyer or other general patient information, but requested the medical technical manual the surgical team used. The ICU staff gladly obliged and I was told that I was the first patient to ever do so.

After a dangerous infection developed at the entry point of the connection of the LVAD electronic controller to the pump, in March 2012, I was placed on the HU list. This is dependent on the patient being in an inotropic state or suffering from life-threatening complications of the LVAD. This development was actually a relief at this point. I would spend the next 127 days in two different hospitals, at times requiring short visits to the ICU whenever a critical issue arose. Again, I was completely dependent on the highly qualified staff at the ICU and they continued to play a major role in my care during this long waiting period, during which I was not allowed to leave the hospital grounds.

Then, on the afternoon of July 31, 2012, I was informed that an organ which fit my physical requirements was available. I was instructed not to eat or drink anything, as the life-saving operation would take place within the next few hours. I immediately informed my family, was prepped by the team and then put to sleep. The transplantation was performed by Professor Christof Schmid. Three days later, I slowly became conscience again and found myself with a strongly beating heart. Then, 14 days later, I was released and began the process of transitioning back to normality. I bought a running watch and closely monitored my progress on my first short walks. Over time, these became brisker walks and I could see improvements on almost a daily basis. By late November 2012, I returned to my job, working only a few hours a day, then transitioning back to full time by mid-2013.

Since then, I have returned to being a fully productive employee, began running quarter marathons, playing softball and even did a short sailplane course, and am also often asked to give talks about my experiences. I now travel regularly for business and leisure and enjoy the company of my friends and family. I was given a once in a lifetime chance and have fully embraced it (Fig. 2).

The teams in both of the ICUs that supported me had a significant role in my care and recovery. On my regular visits to the hospital for routine tests, I often make it a point to visit the wards and ICU where stayed and have kept in touch with them ever since. The bond between my ICU team and the other wards and me will remain. To all of them, I owe my deepest and utmost respect.

Received: 22 October 2018 Accepted: 8 November 2018 Published online: 19 November 2018 